\title{
EFFICIENCY ASSESSMENT OF PUBLIC UNIVERSITIES IN SOUTH AFRICA, 2009-2013: PANEL DATA EVIDENCE
}

\author{
L.W. Myeki* \\ School of Psychology and UNE Business School \\ e-mail: lindikayam@yahoo.co.za \\ O. Temoso* \\ UNE Business School \\ e-mail: otemoso@yahoo.com
}

*University of New England, Armidale

NSW, Australia

\section{ABSTRACT}

With continuous growth of students' enrolments in the public universities and limited funding, assessing the efficiency of universities is vital for effective allocation and utilisation of educational resources. Are higher education institutions in South Africa making the most efficient use of resources made available to them? This study attempts to provide an answer to this question. We apply a Data Envelopment Analysis (DEA) method to estimate technical efficiency (TE) of 22 public universities in South Africa for the period 2009 to 2013. A university is said to be efficient if it is producing maximum output (number of graduates and publications) from a minimum quantity of inputs (staff numbers, students' enrolments, and expenditure). The results indicate that over the study period the average TE of universities declined from 0.83 to 0.78 . Research-intensive universities were more efficient than professional-oriented universities. These results can help key decision-makers such as the Commission on Higher Education and universities management in identifying possibilities for improving institutional performance by identifying their strengths and weaknesses and benchmarking with their peers.

Keywords: technical efficiency, benchmarking, panel data, higher education, South Africa

\section{INTRODUCTION}

Historically, under the apartheid era, the higher education system in South Africa was racially segregated, with unequal quality, and characterised by duplications and inefficiencies (UserCentred Design for Innovative Services and Applications (UFISA) (2017). Since the 1990s, South Africa's higher education system has gone through a lot of changes which have left a long-lasting imprint on the system, its institutions and practices (Council of Higher Education (CHE) 2007, 1). The key focus for democratic South Africa's policies and regulations have pursued to achieve greater equity, efficiency and effectiveness (UFISA 2017). These changes 
range from the National Qualifications Framework to the Green and White Paper on Higher Education which describes the socio-academic duty of universities, a change from a monoculture university that is based on language and race to a multicultural university, with increased access to universities by formerly disadvantaged groups.

Another significant policy implemented was the National Plan for Higher Education (NPHE) which was gazetted in 2001. This policy followed the 1997 White Paper whose objectives were to improve access (raising students' numbers), improve efficiency (optimal use of resources), and enhance the standard of outputs, especially graduates' knowledge and skills, and generation of new knowledge.

Recent data shows that some of the key objectives of the NPHE have been reached or exceeded. For example, according to the CHE report (2016), Outcome 1 - increase participation rate in higher education - was reached in 2013, whilst Outcome 7 - increase equity in access and success - also improved significantly with a significant number of black African students ( $72 \%$ of total headcount) reported to have been enrolled at a South African university in 2016, which is a significant improvement from the 1999 figures (59\%). Similarly, more female than male students were enrolled in higher education (58\%), and hence there were more female graduates than male. Equally, Outcome 2 - increase graduate outputs - increasing the number of students completing their qualification has been achieved, with an exception for the Doctoral $(\mathrm{PhD})$ graduation rate which was unmet $(13 \%$ achieved as compared to $20 \%$ target). Other key areas where equity is still unmet include the senior academic positions and the research landscape in terms of total research outputs such as publications which are still largely dominated by white and males (CHE 2016, 160). Thus, there is evidence that there is progress in achieving equity outcomes particularly those that relate to race and gender participation.

However, remarkably, little is known about the efficiency of the South African higher education sector, even less about the spread of the efficiency of the public universities. Essentially, an important question is whether the post-apartheid policies and programs have helped to bridge the performance (efficiency) gaps between the historically advantaged institutions (historically white) ${ }^{1}$ and historically disadvantaged (historically black) institutions. This study aims to contribute to this question by evaluating the technical efficiency of public universities in South Africa using a panel data of 22 public universities over 2009 to 2013 period. This is worth exploring, given that education has received much attention in terms of policy experiments and government resource allocation in recent times (Van der Berg 2007). Moreover, recent evidence shows that university funding has been declining due to declining government subsidies and fees, as result of Department of Higher Education and Training 
(DHET) responding to the \#FeesMustFall campaigns (Cloete 2016).

According to Fedderke, De Kadt, and Luiz (2003), most of the South African public universities are inefficient. The immediate cause of this inefficiency is the poor quality of incoming university students, limited investment, and poor structural transformation. Cloete (2016) found that there are high dropouts and low graduation rates amongst undergraduates students, which result in them remaining registered for long periods, well beyond the normal times required for the completion of their qualifications. The root causes of this inefficiency include amongst others: lack of sound basic education, political interference, and inappropriate policies. The immediate effects of the inefficiency of public universities in South Africa are unemployment, stagnant development, and lack of trust in public university education system. These lead to social unrest and reduced value of public university education. Collectively, these imply a greater need to improve the efficiency of universities.

For the purpose of this study, TE assessment is considered. Are public universities in South Africa making the most efficient use of resources made available to them? This study seeks to provide the most recent status of the performance of universities and advance the knowledge of education economics in South Africa. The findings from this study are also relevant to policy, as they can be used by key decision-makers for evaluation of public funding, and by the management of universities for benchmarking against their university peers, and use it to take further analysis to identify the various organisational factors (policies, processes, structures, etc.) that account for the observed differences between their organisation and its peers.

The remainder of the study is organised into four sections. The next section provides a literature overview of studies in efficiency and productivity of higher education; after the literature review the methodology is presented under the heading Materials and Methods; after that follow the Results and Discussion; whilst finally the Conclusion follows to conclude the study.

\section{LITERATURE REVIEW}

Prior to evaluation of performance for any firm, it is imperative to describe the best performance, which forms the basis for comparison of the actual performance. In the efficiency and productivity analysis literature, two major methods (Stochastic frontier analysis and Data envelopment) are used to achieve this. The stochastic frontier analysis (SFA) is a parametric method which imposes several neoclassical assumptions in the production process along with specification of functional form. On the other hand, data envelopment analysis (DEA) is a nonparametric method that employs mathematical programming technique that handles multiple 
inputs and outputs without any assumptions and specification of functional form. For this reason, this study uses DEA to derive the relative efficiency of universities.

Globally, there exists extensive literature on efficiency analysis of higher education institutions and most of these literature uses DEA. This section provides an overview of the studies conducted through DEA methodology both globally and in South Africa.

Abbott and Doucouliagos (2003) used DEA to investigate the performance of 36 universities in Australia for the year 1995. They found high levels of efficiency (0.95-1.00) among public universities. Five years later, the authors compared the performance of universities in Australia and New Zealand using DEA and SFA. They found average technical efficiency scores of 0.92 and 0.88 , indicating that Australian universities are performing better compared to New Zealand universities (Abbott and Doucouliagos, 2009).

In Europe, a significant amount of literature has been published on technical efficiency of higher public universities. For instance, Agasisti and Salerno (2007) evaluated the performance of 52 Italian universities for the period 2002 to 2003 and reported an average efficiency of 0.94 . In their study of 45 British universities, Flegg, Allen, Field, and Thurlow (2004) found an overall mean technical efficiency score of 0.88. Recently, the findings of Agasisti and Haelermans (2016) on the efficiency of 71 universities from the years 2005 to 2008, showed the influence of policy direction on efficiency.

In Asia, Aziz, Janor, and Mahadi (2013) employed DEA to assess the efficiency of 22 Malaysian university departments and found a various mix of performance indicators yielding differences inefficiency scores. Alabdulmenem (2017) assessed the performance of 25 Saudi Arabian public universities and found average technical efficiency of 0.90 . Other studies conducted in this continent included Kantabutra and Tang (2010), and Chuanyi, Xiaohong, and Shikui (2016).

In the Americas, earlier studies include McMillan and Datta (1998) who analysed technical efficiency of 45 Canadian universities. The study found the comprehensive universities to characteristically appear as a benchmark for other comprehensive universities, whilst those for the primarily undergraduate institutions mostly come from within that class. A study by Munoz (2016) estimated technical efficiency of 43 universities in Chile from 2013 to 2014 and found that public higher education institutions were more efficient relative to private higher education institutions. Visbal-Cadavid, Martínez-Gómez, and Guijarro (2017) analysed the efficiency of 32 Colombian public universities and concluded that over 50 per cent of universities were efficient.

In Africa, AL-Tyeb (2017) assessed the efficiency of 15 public universities in Egypt using DEA for the year 2013/2014 and found average efficiency of 0.53 indicating 47 per cent 
potential to improve outputs. On the other hand, Bangi (2014) employed a two-stage DEA approach method to determine technical efficiency of Tanzania's private universities for the years 2008 to 2012, and found average technical efficiency of 0.93 . Collectively, the results of DEA assessment of efficiency show high technical efficiency scores of universities around the world.

In South Africa, only Taylor and Harris (2004) have employed a DEA method to estimate the efficiency of public universities. Some of the key findings from the study include, maintaining graduate output improves efficiency levels of universities; graduation rates in some universities was partly associated with the general higher qualification base of the academic staff; and raising the fixed costs is associated with a decrease of efficiency (Taylor and Harris 2004, 84). While this study lays the foundation for an analysis of efficiency in South Africa, it is old, some universities and policies were non-existent when it was conducted. Therefore, the current study provides an up to date picture of the efficiency of South African universities using recent data.

\section{MATERIALS AND METHODS}

\section{Data}

The current study uses data obtained from the Department of Higher Education and Training (DHET) in South Africa covering five years (2009-2013). DHET draws and collates data from several information systems and databases. These include among others the Higher Education Management Information System (HEMIS), Further Education and Training Management Information System (FETMIS), The Sector Education and Training Authority (SETA), and National Skills Fund (NSF). DHET uses its processes to perform data quality checks on a continuous basis.

The sample consists of 22 public universities located in 7 provinces of South Africa. Five are in Gauteng Province; four in Western Cape and Eastern Cape Province; three in Kwa-Zulu Natal Province; two in Free State and Limpopo Province, and; one in North West Province. In total this sample represents 85 per cent of public universities in South Africa. It should be noted that Sol Plaatje University located in Northern Cape Province, University of Mpumalanga (Mpumalanga Province), University of Technology (Kwa-Zulu Natal Province), and Sefako Makgatho Health Science University (Gauteng Province) are excluded in the sample due to lack of Masters and PhD students.

Like other countries, South African universities are multiple inputs and multiple output organisations. This therefore requires careful selection of performance indicators. According to 
Katharaki and Katharakis (2010) criterion, indicators must satisfy the mission of the university, be standardised and expressed as quantity, consistent among all the universities, and satisfy the tasks for which they will be a reference for a decision. This criterion along with previous literature (e.g. Abbott and Doucouliagos 2003; Johnes 2014; Marire 2017) and economic theory on efficiency analysis were used for selection of performance indicators in the present study. These performance indicators are presented in Table 1.

The input variables include the undergraduate students enrolled (X1), the postgraduate students enrolled (X2), academic staff for teaching or teaching and research or research only (X3), and the total budget expenditure (X4). On the other hand, the output variables were weighted research output $(\mathrm{Q} 1)$ and weighted graduates $(\mathrm{Q} 2)$.

Table 1: Definition of input-output performance indicators

\begin{tabular}{|c|c|c|}
\hline Variable & Unit & Definition \\
\hline \multicolumn{3}{|l|}{ Outputs: } \\
\hline Q1 & & $\begin{array}{l}\text { Weighted research output - i.e. doctoral graduates, research masters } \\
\text { graduates, and research publication units }\end{array}$ \\
\hline Q2 & Persons & $\begin{array}{l}\text { Weighted graduates - undergraduates up to thought masters students. } \\
\text { Weighting factors from DHET are } 0.5 \text { for undergraduate and postgraduates }\end{array}$ \\
\hline \multicolumn{3}{|r|}{ - } \\
\hline $\mathrm{X} 1$ & Persons & Total number of undergraduate students enrolled \\
\hline $\mathrm{X} 2$ & Persons & Total number of postgraduate students enrolled \\
\hline X3 & Persons & $\begin{array}{l}\text { Total number of academic staff for teaching or teaching and research or } \\
\text { research only purposes }\end{array}$ \\
\hline $\mathrm{X} 4$ & Million Rand & Total expenditure - deflated with CPI \\
\hline
\end{tabular}

\section{Model}

In the seminal work of Farrell (1957), efficiency refers to the firm's potential to generate utmost outputs given a fixed level of inputs. Farrell divides efficiency into allocative efficiency (AE) and technical efficiency (TE). The former (AE) can be defined as utilisation of inputs in optimal proportions to generate a given quantity of output at low cost, with the existing technology and input prices, whereas the later, TE estimates the potential of a firm to generate maximum output from fixed inputs, or achieve a certain output threshold using minimum quantities of inputs within a given technology (Farrell 1957).

Based on multiple performance indicators of South African public universities, the nonparametric DEA was preferred. This model has been widely used in previous studies (e.g., Taylor and Harris, 2004), and originates from Charnes, Cooper, and Rhodes (1978). It uses linear programming to develop an efficiency frontier known as piece-wise that forms the basis for comparative assessment of firms' efficiency. This efficiency is estimated in terms of: "Input orientation" - the quantity of utmost output generated with a set of inputs, and; "Output orientation" - the quantity by which output can be raised while holding inputs fixed. The DEA 
approach considers the existing production technology of the firm, and this is classified into constant returns to scale (CRS) and variable returns to scale (VRS). Because scale effects need to be disentangled to obtain pure technical efficiency, input-oriented VRS DEA model can be expressed as follows:

$$
\begin{array}{ll}
\operatorname{Min}_{\theta, \lambda} & \\
\text { st } \quad-\mathrm{q}_{i}+\mathrm{Q} \lambda \geq 0 \\
& \theta \mathrm{x}_{i}-\mathrm{X} \lambda \geq 0 \\
& \mathrm{I} 1^{\prime} \lambda=1 \\
& \lambda \geq 0
\end{array}
$$

Where: $\mathrm{x}_{\mathrm{i}}$ is an $N \mathrm{x} 1$ vector of inputs of the individual ( $i$-th) university; $\mathrm{q}_{\mathrm{i}}$ is $M \mathrm{x} 1$ vector of outputs of the individual ( $i$-th) university; $\mathrm{X}$ is a $N \mathrm{x}$ I input matrix; $\mathrm{Q}$ is $M \mathrm{x}$ I output matrix; $\theta$ is a scalar (used to estimate TE), $\lambda$ is a I x 1 vector of constants; I1 is an Ix 1 vector of ones.

In this study the DEA model was estimated using DEAP, a computer program developed using FORTRAN.

\section{RESULTS AND DISCUSSION}

This section presents the descriptive statistics of input-output performance indicators, followed by a discussion of technical efficiency scores for the universities. A further discussion includes peers and peer-weights which provides a tool that can be used by universities to benchmark against their peers and assess their performance through slacks (the input surpluses), and targets (the desirable levels of inputs).

\section{Descriptive statistics of input and output variables}

The descriptive statistics of inputs and outputs variables employed in the analysis are shown in Table 2 below. As can be seen from the table, the dataset was composed of two outputs and four inputs. The outputs include weighted research output, with an average of 801.49 and weighted graduates with an average of 6,409. Inputs included number of undergraduates, average of 33,712, number of postgraduates, average of 6,582, number of academic staff, average of 1,037 and expenditure, average of 361,391 Rands.

In year 2009, the UP was the biggest producer of research outputs, accounting for 2,146 (14\%) units of the total research outputs, followed by UKZN $(1,756)$, SU $(1,723)$, UCT $(1,692)$, and WITS $(1,474)$, respectively. The largest producers of graduate outputs were UNISA, TUT, UP, NWU and the UJ. 
Table 2: Descriptive statistics of input and output variables

\begin{tabular}{|c|c|c|c|c|c|c|c|c|c|}
\hline Variables & Type & Units & Parameters & 2009 & 2010 & 2011 & 2012 & 2013 & All \\
\hline \multirow{4}{*}{$\begin{array}{l}\text { Weighted research } \\
\text { output }\end{array}$} & \multirow[t]{4}{*}{ Output 1} & \multirow[t]{4}{*}{$\mathrm{N}$} & Mean & 692.58 & 712.62 & 792.03 & 847.78 & 962.42 & 801.49 \\
\hline & & & Standard deviation & 674.79 & 707.77 & 760.93 & 785.20 & 849.70 & 750.56 \\
\hline & & & Min & 24.56 & 22.65 & 29.51 & 56.73 & 67.10 & 22.65 \\
\hline & & & $\operatorname{Max}$ & 2145.79 & 2219.23 & 2287.09 & 2388.45 & 2603.06 & 2603.06 \\
\hline \multirow[t]{4}{*}{ Weighted graduates } & \multirow[t]{4}{*}{ Output 2} & \multirow[t]{4}{*}{$P$} & Mean & 5668.24 & 6029.70 & 6331.67 & 6688.23 & 7327.79 & 6409.13 \\
\hline & & & Standard deviation & 3800.57 & 4341.26 & 4530.84 & 4453.18 & 5792.58 & 4580.52 \\
\hline & & & Min & 1502.75 & 1543.00 & 1689.63 & 1799.63 & 1816.45 & 1502.75 \\
\hline & & & Max & 17124.07 & 20685.26 & 21814.34 & 21755.59 & 29152.14 & 29152.14 \\
\hline \multirow{4}{*}{$\begin{array}{l}\text { Number of } \\
\text { undergraduate students } \\
\text { enrolled }\end{array}$} & \multirow[t]{4}{*}{ Input 1} & \multirow[t]{4}{*}{$P$} & Mean & 30669.95 & 32584.05 & 34385.68 & 35041.27 & 35880.82 & 33712.35 \\
\hline & & & Standard deviation & 43979.73 & 48832.91 & 54863.04 & 56674.61 & 58875.52 & 51982.20 \\
\hline & & & Min & 5318.00 & 5246.00 & 5237.00 & 5243.00 & 5130.00 & 5130.00 \\
\hline & & & $\operatorname{Max}$ & $\begin{array}{c}220347.0 \\
0\end{array}$ & 244764.00 & 274389.00 & 283335.00 & 293904.00 & 93904.00 \\
\hline \multirow{4}{*}{$\begin{array}{l}\text { Number of postgraduate } \\
\text { students enrolled. }\end{array}$} & \multirow[t]{4}{*}{ Input 2} & \multirow[t]{4}{*}{$P$} & Mean & 5852.14 & 6300.45 & 6722.41 & 6773.91 & 7261.36 & 6582.05 \\
\hline & & & Standard deviation & 7039.72 & 7879.14 & 8960.79 & 8822.68 & 10004.35 & 8454.92 \\
\hline & & & Min & 203.00 & 186.00 & 207.00 & 213.00 & 319.00 & 186.00 \\
\hline & & & $\operatorname{Max}$ & 29027.00 & 33707.00 & 39456.00 & 38644.00 & 45494.00 & 45494.00 \\
\hline \multirow{4}{*}{$\begin{array}{l}\text { Number of academic } \\
\text { staff }\end{array}$} & \multirow[t]{4}{*}{ Input 3} & \multirow[t]{4}{*}{$P$} & Mean & 965.94 & 990.80 & 1049.59 & 1086.58 & 1093.94 & 1037.37 \\
\hline & & & Standard deviation & 559.63 & 560.28 & 594.51 & 629.32 & 662.14 & 593.56 \\
\hline & & & Min & 294.48 & 314.40 & 316.28 & 319.03 & 325.30 & 294.48 \\
\hline & & & Max & 2020.06 & 1980.18 & 2064.92 & 2151.67 & 2541.45 & 2541.45 \\
\hline \multirow[t]{4}{*}{ Total expenditure } & \multirow[t]{4}{*}{ Input 4} & \multirow[t]{4}{*}{$\mathrm{R}$} & Mean & $\begin{array}{c}43 \\
063.40 \\
\end{array}$ & 500977.36 & 286137.69 & 354815.48 & 421961.273 & 361391.04 \\
\hline & & & Standard deviation & $\begin{array}{c}61 \\
400.75\end{array}$ & 320945.39 & 88521.46 & 36111.84 & 269425.212 & 255123.2497 \\
\hline & & & Min & $\begin{array}{c}59 \\
123.86 \\
\end{array}$ & 119226.65 & 72545.73 & 90186.06 & 112428.244 & 59123.86 \\
\hline & & & Max & $\begin{array}{c}41 \\
135.71\end{array}$ & 1090464.67 & 34944.30 & 800491.05 & 955888.931 & 1090464.67 \\
\hline
\end{tabular}


The top five producers of research outputs in the year 2013 were the UP, UCT, SU, UKZN and WITS whereas UNISA, TUT, UP, NWU and UJ remained as top producers of graduate outputs. Collectively, the results indicate that traditional universities (research-focused universities) perform better on both research and graduate outputs whereas comprehensive (professionaloriented) and universities of technology (practical oriented) show greater performance on graduate outputs. This variation of findings can be attributed to the orientation and the age of the university.

\section{Efficiency performance of the universities}

The key purpose of the study was to estimate the efficiency of South African public universities using DEA. The values of technical efficiency range from zero (technically inefficient) to one (technically efficient). The analysis is presented in Figure 1 and 2 (with more details provided in Appendix A).

In 2009, a typical public university had an average technical efficiency of 0.83 indicating the potential to increase outputs (research and graduates) by 17 per cent without changing the inputs. These ranged from the least efficient university with TE score of 0.34 (TUT) to the most efficient institution with a TE score of 1.00 (CPUT, UCT, UFH, UFS, UJ, NWU, RU, UNISA, SU, VUT and WITS).

In 2013, an average public university had a technical efficiency score of 0.78 indicating the potential to increase outputs (research and graduates) by 22 per cent without changing the inputs. This ranged from 0.31 (TUT) to 1.00 (the UCT, UFS, NMU, NWU, RU, SU, UNIVEN, WSU, UWC and WITS).

As shown in Figure 1, over the study period, the most efficient universities in South Africa are generally those that are research-intensive, and historical "white" universities which were strategically located, resourced and conducted most of research in South Africa (i.e. UCT, UFS, RU, SU, and WITS) (UFISA 2017). On the other hand, the three least efficient institutions are TUT, DUT and CPUT, respectively. These are vocationally oriented institutions, formerly Technikons (polytechnics), awarding variety of qualifications such as higher certificates, diplomas and degrees in technology; and have limited postgraduate and research capacity (UFISA 2017). Comprehensive universities or institutions offering both bachelor and technology qualifications, with a focus on teaching and also conduct research and postgraduate study, performed moderately in terms of technical efficiency across the study period. These include UNISA and UJ amongst others. 


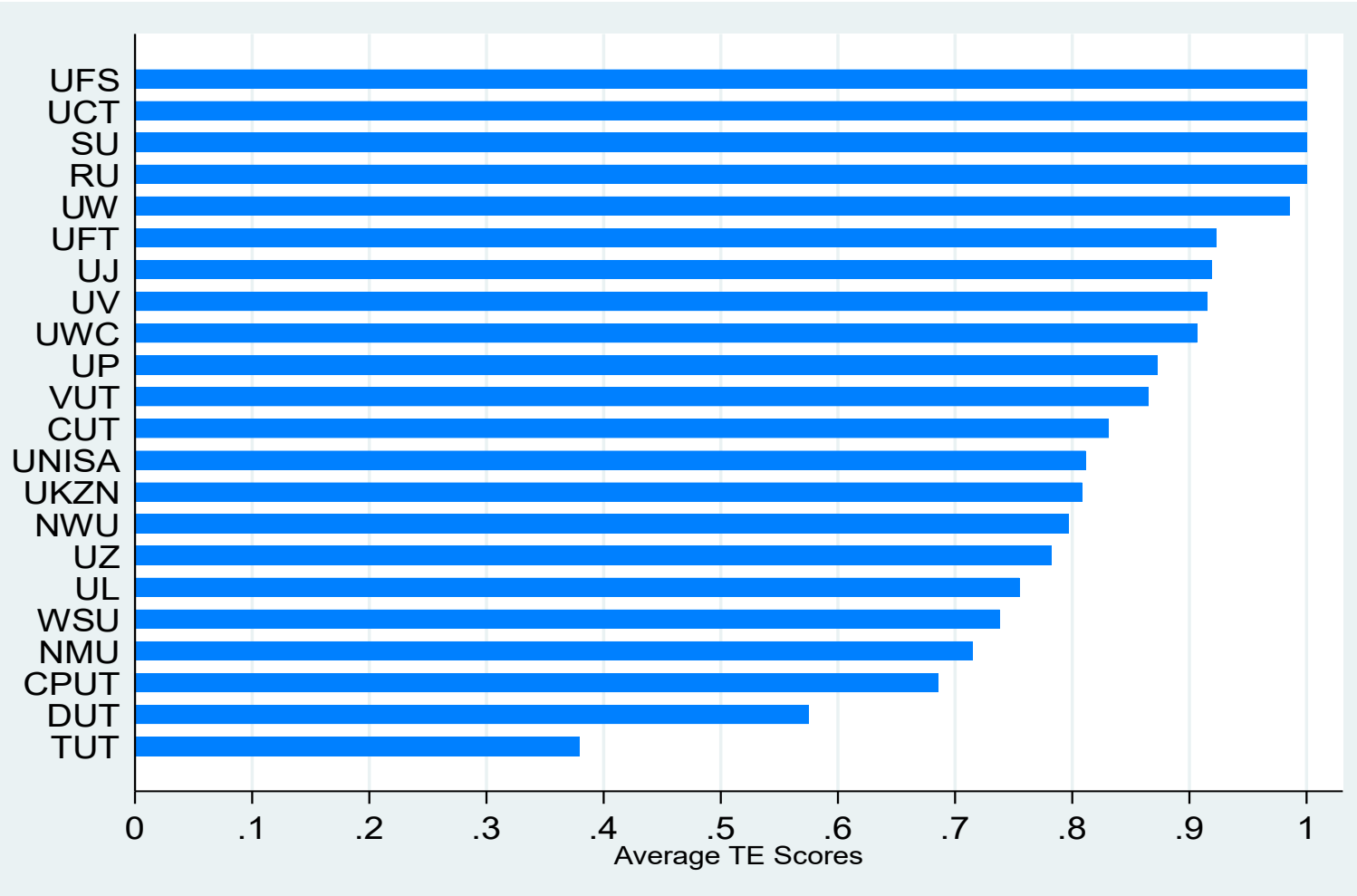

Figure 1: The average TE scores for the South African universities, 2009 to 2013

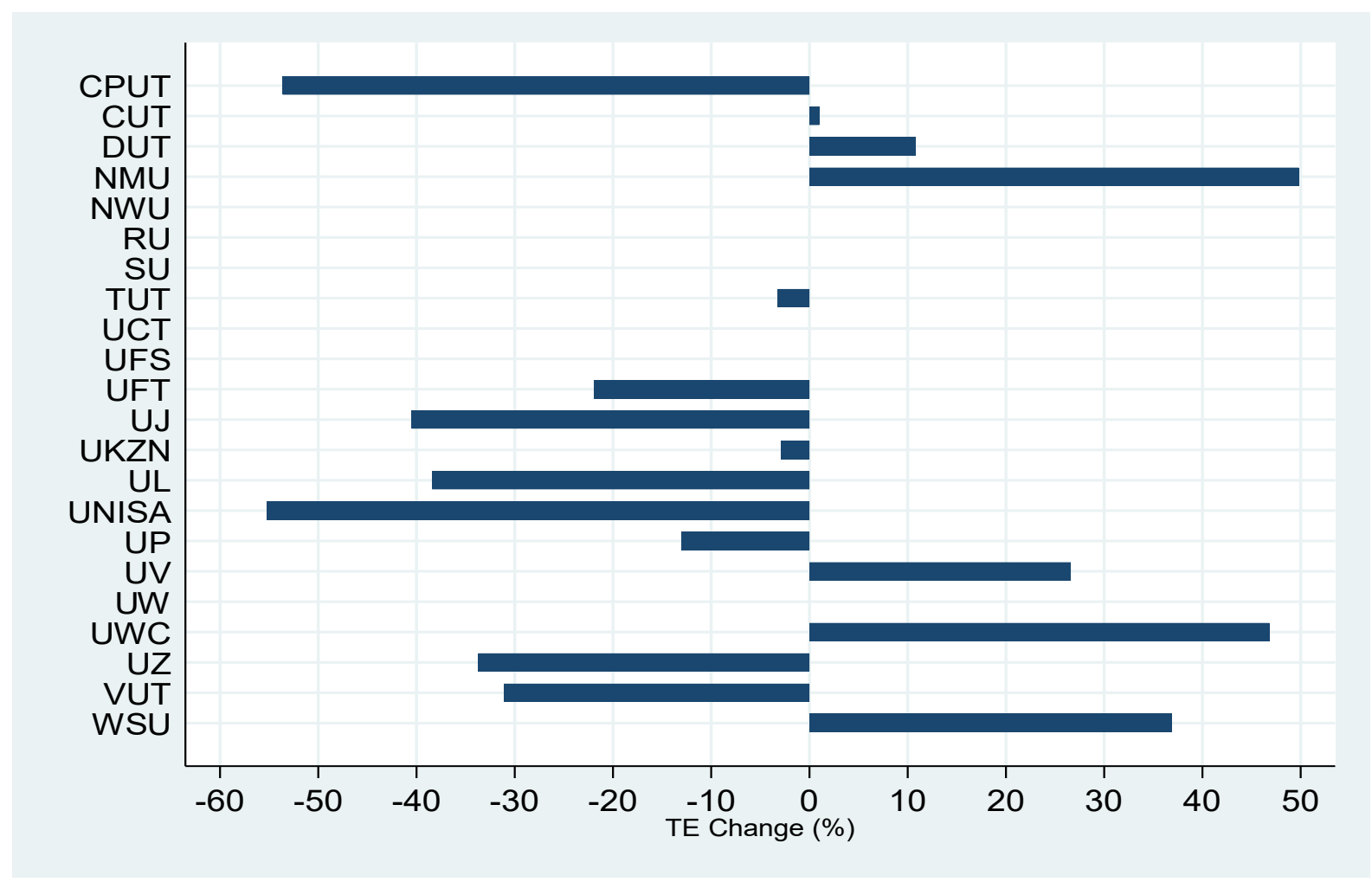

Figure 2: Technical Efficiency Change, 2009 to 2013 


\section{How much additional improvement (increase in outputs and/or decrease in inputs) is needed for a university to become efficient?}

One of the key advantages of using DEA is its ability to provide insights on how much universities should enhance their technical efficiency by identifying over-utilisation (underutilisation) of inputs (outputs) through input (output) slacks. Table 3 present the input slacks or the amount by which each input can be reduced while keeping the outputs unchanged. Over the period, the potential increase for undergraduates' enrolment averaged 0.09 per cent, whilst academic staff numbers and total expenditure averaged 0.36 per cent and 0.21 per cent, respectively. The overall results show that South African public universities had the potential to reduce the academic staff and total expenditure without changing the current outputs. However, the analysis showed no potential reduction in undergraduates and postgraduates.

Table 3: Input Slacks

\begin{tabular}{|c|c|c|c|c|}
\hline \multirow{2}{*}{ University } & \multicolumn{4}{|c|}{ Input Slacks } \\
\hline & $\mathbf{I S}_{1}$ & $\mathbf{I S}_{2}$ & $\mathbf{I S}_{3}$ & $\mathrm{IS}_{4}$ \\
\hline CPUT & 0.00 & 0.00 & 0.00 & 0.00 \\
\hline UCT & 0.00 & 0.00 & 0.00 & 0.00 \\
\hline CUT & 0.00 & 0.00 & 1.00 & 1.00 \\
\hline DUT & 1.00 & 0.00 & 0.00 & 0.00 \\
\hline UFH & 0.00 & 0.00 & 0.00 & 0.00 \\
\hline UFS & 0.00 & 0.00 & 0.00 & 0.00 \\
\hline UJ & 0.00 & 0.00 & 0.00 & 0.00 \\
\hline UKZN & 0.00 & 0.00 & 0.00 & 1.00 \\
\hline UL & 0.00 & 0.00 & 1.00 & 0.00 \\
\hline NMU & 0.00 & 0.00 & 1.00 & 0.00 \\
\hline NWU & 0.00 & 0.00 & 0.00 & 0.00 \\
\hline UP & 0.00 & 0.00 & 1.00 & 0.00 \\
\hline RU & 0.00 & 0.00 & 0.00 & 0.00 \\
\hline UNISA & 0.00 & 0.00 & 0.00 & 0.00 \\
\hline SU & 0.00 & 0.00 & 0.00 & 0.00 \\
\hline TUT & 1.00 & 0.00 & 0.00 & 0.00 \\
\hline VUT & 0.00 & 0.00 & 0.00 & 0.00 \\
\hline UNIVEN & 0.00 & 0.00 & 1.00 & 1.00 \\
\hline WSU & 0.00 & 0.00 & 1.00 & 0.00 \\
\hline UWC & 0.00 & 0.00 & 1.00 & 1.00 \\
\hline WITS & 0.00 & 0.00 & 0.00 & 0.00 \\
\hline UZ & 0.00 & 0.00 & 1.00 & 0.51 \\
\hline Mean & 0.09 & 0.00 & 0.36 & 0.21 \\
\hline Standard Deviation & 0.29 & 0.00 & 0.49 & 0.40 \\
\hline
\end{tabular}

$\mathrm{IS}_{1}=$ number of undergraduate students enrolled; $\mathrm{IS}_{2}=$ number of postgraduate students enrolled; $\mathrm{IS}_{3}=$ number of academic staff for teaching or teaching and research or research only purposes; $I S_{4}=$ total expenditure 


\section{Input targets: What are the optimal levels of inputs to improve technical}

\section{efficiency?}

DEA yields useful information that helps to place input slacks in their rightful position. This information is known as input targets - that is the average desirable level of each input that each university can target to generate the desired maximum output optimally. In estimating the targets, the amount of inputs used are compared with the amount of target input estimated by the model, together with the proportional increase needed to achieve the target. For the current study, the input targets are presented in Table 4. Over the period, the average desired level of undergraduate enrolment was 3.13 per cent ranging from -0.84 per cent (WITS) to 43.17 per cent (UFS). For postgraduates, the average desired level was 0.16 per cent with a range from -0.98 per cent (UJ) to 3.28 (UFH). Furthermore, academic staff averaged 1.19 per cent ranging from -0.95 per cent (NWU) to 20.35 per cent (UFS). Finally, average desired total expenditure was 0.45 per cent ranging from -0.99 per cent (WSU) to 7.29 per cent (CPUT).

Table 4: Input targets

\begin{tabular}{|c|c|c|c|c|}
\hline University & $\mathrm{IT}_{1}$ & $\mathrm{IT}_{2}$ & $\mathrm{IT}_{3}$ & $\mathrm{IT}_{4}$ \\
\hline CPUT & -0.48 & -0.61 & -0.50 & 7.29 \\
\hline UCT & -0.47 & 0.25 & -0.36 & 0.07 \\
\hline CUT & 0.52 & 0.02 & 0.38 & -0.19 \\
\hline DUT & 0.56 & 0.54 & 0.33 & -0.26 \\
\hline UFH & -0.30 & 3.28 & -0.12 & -0.41 \\
\hline UFS & 43.17 & -0.91 & 20.35 & -0.79 \\
\hline UJ & 11.37 & -0.98 & 1.37 & -0.97 \\
\hline UKZN & -0.76 & 0.28 & -0.48 & 0.21 \\
\hline UL & -0.25 & 1.04 & -0.16 & 0.03 \\
\hline NMU & 1.99 & -0.20 & 1.45 & -0.81 \\
\hline NWU & 4.97 & 0.33 & -0.95 & 0.27 \\
\hline UP & 0.42 & 0.06 & -0.83 & -0.16 \\
\hline RU & 0.00 & 0.62 & 0.00 & -0.59 \\
\hline UNISA & 6.03 & -0.90 & -0.69 & -0.62 \\
\hline SU & -0.67 & 0.00 & 3.38 & 0.07 \\
\hline TUT & 0.05 & -0.13 & -0.18 & 1.91 \\
\hline VUT & -0.08 & 0.06 & -0.32 & 3.86 \\
\hline UNIVEN & 0.36 & -0.95 & 0.56 & 0.21 \\
\hline WSU & 1.64 & -0.23 & 1.81 & -0.99 \\
\hline UWC & 1.82 & 0.38 & 1.89 & 2.00 \\
\hline WITS & -0.84 & 0.50 & -0.81 & 0.05 \\
\hline UZ & -0.15 & 1.00 & 0.02 & -0.32 \\
\hline Mean & 3.13 & 0.16 & 1.19 & 0.45 \\
\hline Standard Deviation & 9.39 & 0.92 & 4.42 & 1.90 \\
\hline
\end{tabular}

Note. IT = Input Target in percentages 


\section{Who are the universities peers: Which universities to benchmark with to improve efficiency?}

Another important information obtained from DEA results is the group of best practice or "role models" known as peers. Peer universities are those listed as efficient by the model, and which inefficient university may emulate to improve its performance. Table 5 presents the peers and peer-weights for the study in 2009. It should be noted that the higher the peer-weight the more crucial that university is a peer for the inefficient university in question. For instance, CUT has two peers, UFH and RU with peer-weights of 0.43 and 0.57 , respectively. This implies that CUT should emulate RU. Similarly, DUT must emulate UFH, whereas UKZN should imitate WITS. The top three role models were RU, UFS and UFH.

Table 5: Peers and peer-weights for 2009

\begin{tabular}{|c|l|c|c|c|c|c|c|c|c|}
\hline \multirow{2}{*}{$\begin{array}{c}\text { University } \\
\text { ID number }\end{array}$} & \multicolumn{4}{|c|}{ University } & \multicolumn{2}{|c|}{ Input-oriented VRS } \\
\hline 1 & CPUT & 1 & - & - & - & - & - & - & - \\
\hline 2 & UCT & 2 & - & - & - & - & - & - & - \\
\hline 3 & CUT & 5 & 13 & - & - & 0.433 & 0.567 & - & - \\
\hline 4 & DUT & 13 & 6 & 5 & & 0.092 & 0.360 & 0.548 & - \\
\hline 5 & UFH & 5 & - & - & - & - & - & - & - \\
\hline 6 & UFS & 6 & - & - & - & - & - & - & - \\
\hline 7 & UJ & 7 & - & - & - & - & - & - & - \\
\hline 8 & UKZN & 15 & 11 & 21 & - & 0.316 & 0.009 & 0.675 & - \\
\hline 9 & UL & 13 & 6 & 5 & - & 0.173 & 0.392 & 0.435 & - \\
\hline 10 & NMU & 5 & 6 & 13 & - & 0.054 & 0.318 & 0.628 & - \\
\hline 11 & NWU & 11 & - & - & - & - & - & - & - \\
\hline 12 & UP & 21 & 6 & 11 & 1 & 0.160 & 0.001 & 0.837 & 0.001 \\
\hline 13 & RU & 13 & - & - & - & - & - & - & - \\
\hline 14 & UNISA & 14 & - & - & - & - & - & - & - \\
\hline 15 & SU & 15 & - & - & - & - & - & - & - \\
\hline 16 & TUT & 17 & 6 & 13 & - & 0.568 & 0.369 & 0.063 & - \\
\hline 17 & VUT & 17 & - & - & - & - & - & - & - \\
\hline 18 & UNIVEN & 5 & 13 & - & - & 0.468 & 0.532 & - & - \\
\hline 19 & WSU & 6 & 13 & 5 & - & 0.166 & 0.438 & 0.395 & - \\
\hline 20 & UWC & 5 & 13 & - & - & 0.065 & 0.935 & - & - \\
\hline 21 & WITS & 21 & - & - & - & - & - & - & - \\
\hline 22 & UZ & 5 & 13 & - & - & 0.710 & 0.290 & - & - \\
\hline
\end{tabular}

Note. IS = Input Slack

In 2013 (Table 6), CUT had four peers that are RU, UNIVEN, NWU and WSU. Since the peerweight for UNIVEN is higher than the other comparators, CUT should emulate UNIVEN. Other universities that should emulate UNIVEN include CPUT and UZ. On the other hand, UJ, UKZN and UP, should emulate WITS. The top comparators were UNIVEN, NWU, RU, WSU and WITS. From the above analysis, we can conclude that the top benchmark universities represent a diverse group of universities - small universities tend to benchmark against other small, whilst research-intensive universities benchmark against other research-intensive, etc. This is 
consistent with the literature, for example, in Canada, McMillan and Datta (1998) found comprehensive universities to characteristically appear as a benchmark for other comprehensive universities, whilst those that are primarily undergraduate institutions mostly come from within that class.

Table 6: Peers and peer-weights for 2013

\begin{tabular}{|c|c|c|c|c|c|c|c|c|c|c|c|}
\hline \multirow{2}{*}{$\begin{array}{c}\text { University } \\
\text { ID number }\end{array}$} & \multirow{2}{*}{ University } & \multicolumn{5}{|c|}{ Peers } & \multicolumn{6}{|c|}{ Input-oriented VRS } \\
\hline 1 & CPUT & 10 & 19 & 18 & 11 & 13 & 0.78 & 0.171 & 0.648 & 0.002 & 0.001 \\
\hline 2 & UCT & 2 & - & - & - & - & 1 & - & - & - & - \\
\hline 3 & CUT & 13 & 18 & 11 & 19 & - & 0.394 & 0.553 & 0.001 & 0.052 & - \\
\hline 4 & DUT & 13 & 19 & 18 & 11 & - & 0.128 & 0.403 & 0.467 & 0.002 & - \\
\hline 5 & UFH & 13 & 18 & - & - & - & 0.594 & 0.406 & - & - & - \\
\hline 6 & UFS & 6 & - & - & - & - & 1 & - & - & - & - \\
\hline 7 & UJ & 21 & 11 & - & - & - & 0.909 & 0.091 & - & - & - \\
\hline 8 & UKZN & 21 & 6 & 18 & 2 & - & 0.561 & 0.366 & 0.002 & 0.071 & - \\
\hline 9 & UL & 11 & 13 & 19 & 18 & - & 0 & 0.362 & 0.081 & 0.557 & - \\
\hline 10 & NMU & 10 & - & - & - & - & 1 & - & - & - & - \\
\hline 11 & NWU & 11 & - & - & - & - & 1 & - & - & - & - \\
\hline 12 & UP & 11 & 19 & 21 & - & - & 0.326 & 0.005 & 0.669 & - & - \\
\hline 13 & RU & 13 & - & - & - & - & 1 & - & - & - & - \\
\hline 14 & UNISA & 11 & 19 & 18 & 21 & - & 0.168 & 0.016 & 0.244 & 0.573 & - \\
\hline 15 & SU & 15 & - & - & - & - & 1 & - & - & - & - \\
\hline 16 & TUT & 10 & 19 & 13 & 18 & - & 0.297 & 0.138 & 0.205 & 0.36 & - \\
\hline 17 & VUT & 13 & 19 & 18 & - & - & 0.513 & 0.423 & 0.064 & - & - \\
\hline 18 & UNIVEN & 18 & - & - & - & - & 1 & - & - & - & - \\
\hline 19 & WSU & 19 & - & - & - & - & 1 & - & - & - & - \\
\hline 20 & UWC & 20 & - & - & - & - & 1 & - & - & - & - \\
\hline 21 & WITS & 21 & - & - & - & - & 1 & - & - & - & - \\
\hline 22 & UZ & 13 & 18 & - & - & - & 0.549 & 0.451 & - & - & - \\
\hline
\end{tabular}

Note. IS = Input Slack

\section{CONCLUSION}

The main purpose of this study was to measure technical efficiency of South African public universities using a DEA approach and recent data. This is the first attempt for a DEA study on higher education performance in South Africa using recent data.

Over the period, the average TE for the universities declined from 0.83 in 2009 to 0.78 in 2013. This implies reduced ability of universities to maximise their output with a given level of inputs. Over the study period, the UCT, SU, RU and UFS (research-intensive universities) were the most efficient, whilst the DUT, CPUT and TUT (professional-oriented universities) were the least efficient. Comprehensive universities or those institutions that offer both undergraduate and postgraduate degrees, and conduct research, performed moderately in terms of technical efficiency. 
The study also provided information on potential targets and peers that least performing universities can benchmark against to improve their performance. We identified over-utilisation of undergraduates with an excess of 5 people above the optimal size whereas postgraduates, academic staff and total expenditure were in excess of 19 people, 23 people and 27 million Rand, respectively. The top five role models (university benchmarks) were: NWU, SU, UFH, WSU and RU.

The empirical evidence from this study provides information on the current state of efficiency performance of the higher education sector in South Africa. Such insights can inform policy and decision-makers such as the Commission on Higher Education and universities management in formulating targeted interventions that improves the efficiency and competitiveness of universities.

The results also provide insights that can help universities see their standing relative to their peers, and for effective allocation and utilisation of educational resources. However, many strategies for increasing efficiency require changes of the management culture and mindset, therefore, for effectiveness, the supplementary analysis must be done at the individual university to identify the various organisational factors (policies, processes, structures, etc.) that account for the observed differences between their organisation and its peers.

\section{NOTE}

1. Well established institutions with significant resources that were devoted to quality assurance initiatives during the apartheid era.

\section{REFERENCES}

Abbott, M. and C. Doucouliagos. 2003. The efficiency of Australian universities: A data envelopment analysis. Economics of Education Review 22(1): 89-97.

Abbott, M. and C. Doucouliagos. 2009. Competition and efficiency: Overseas students and technical efficiency in Australian and New Zealand universities. Education Economics 17(1): 31-57.

Agasisti, T. and C. Haelermans. 2016. Comparing efficiency of public universities among E European Countries: Different incentives lead to different performances. Higher Education Quarterly 70(1): 81-104.

Agasisti, T. and C. Salerno. 2007. Assessing the cost efficiency of Italian universities. Education Economics 15(4): 455-471

AL-Tyeb, L. E. 2017. The efficiency for education using data envelopment analysis. Journal of Multidisciplinary Engineering Science and Technology 4(3): 6845-6850.

Alabdulmenem, F. M. 2017. Measuring the efficiency of public universities: Using data envelopment analysis (DEA) to examine public universities in Saudi Arabia. International Education Studies 10(1): 137-143.

Aziz, N. A. A., R. M. Janor and R. Mahadi. 2013. Comparative departmental efficiency analysis within a university: A DEA approach. Procedia-Social and Behavioral Sciences 90: 540-548.

Bangi, Y. I. 2014. Efficiency assessment of Tanzanian private universities: Data envelopment analysis (DEA). International Journal of Education and Research 2(5). 
Charnes, A., W. W. Cooper and E. Rhodes. 1978. Measuring the efficiency of decision-making units. European Journal of Operational Research 2(6): 429-444.

Chuanyi, W., L. Xiaohong and Z. Shikui. 2016. The relative efficiencies of research universities of science and technology in China: Based on the data envelopment analysis and Stochastic frontier analysis. Eurasia Journal of Mathematics, Science \& Technology Education 12(10).

Cloete, N., 2016. For sustainable funding and fees, the undergraduate system in South Africa must be restructured. South African Journal of Science 112(3-4): 1-5.

CHE see Council of Higher Education.

Council of Higher Education. 2016. South African higher education reviewed: Two decades of democracy. Pretoria, South Africa.

Council of Higher Education. 2007. Review of higher education in South Africa: Selected themes. Pretoria, South Africa. https://www.che.ac.za/sites/default/files/publications/Review_HE_SA_ 2007_Complete_0.pdf

Farrell, M. J. 1957. The measurement of productive efficiency. Journal of the Royal Statistical Society: Series A (General) 120(3): 253-281.

Fedderke, J., R. De Kadt and J. Luiz. 2003. Capstone or deadweight? Inefficiency, duplication and inequity in South Africa's tertiary education system, 1910-93. Cambridge Journal of Economics 27(3): 377-400.

Flegg, A. T., D. O. Allen, K. Field and T. W. Thurlow. 2004. Measuring the efficiency of British universities: A multi-period data envelopment analysis. Education Economics 12(3): 231-249.

Johnes, Jill. 2014. Efficiency and mergers in English higher education 1996/97 to 2008/9: Parametric and nonparametric estimation of the multi-input multi-output distance function. The Manchester School 82(4): 465-487.

Kantabutra, S. and J. C. Tang. 2010. Efficiency analysis of public universities in Thailand. Tertiary Education and Management 16(1): 15-33.

Katharaki, M. and G. Katharakis. 2010. A comparative assessment of Greek universities' efficiency using quantitative analysis. International Journal of Educational Research 49(4-5): 115-128.

Marire, J. 2017. Are South African public universities economically efficient? Reflection amidst higher education crisis. South African Journal of Higher Education 31(3): 116-137.

McMillan, M. L. and D. Datta. 1998. The relative efficiencies of Canadian universities: A DEA perspective. Canadian Public Policy/Analyse de Politiques 24(4): 485-511.

Munoz, D. A. 2016. Assessing the research efficiency of higher education institutions in Chile: A data envelopment analysis approach. International Journal of Educational Management 30(6): 809825.

Taylor, B. and G. Harris. 2004. Relative efficiency among South African universities: A data envelopment analysis. Higher Education 47(1): 73-89.

UFISA see User Centered Design for Innovative Services and Applications.

User Centered Design for Innovative Services and Applications. 2017. South African Higher Education: Facts and Figures. Higher Education in Context. http://ufisa.aalto.fi/en/network/cput/ facts_figures_section.pdf

Van der Berg, S. 2007. Apartheid's enduring legacy: Inequalities in education. Journal of African Economies 16(5): 849-880.

Visbal-Cadavid, D., M. Martínez-Gómez and F. Guijarro. 2017. Assessing the efficiency of public universities through DEA. A case study. Sustainability 9(8): 1416. 
Appendix A: Technical efficiency of universities in South Africa, 2009 to 2013

\begin{tabular}{|c|c|c|c|c|c|c|c|c|c|c|c|c|}
\hline \multirow[b]{2}{*}{ University } & \multicolumn{6}{|c|}{ Technical Efficiency Scores } & \multicolumn{6}{|c|}{ Ranking by Technical Efficiency Scores } \\
\hline & 2009 & 2010 & 2011 & 2012 & 2013 & $\begin{array}{c}\text { Average } \\
2009 \text { to } \\
2013\end{array}$ & 2009 & 2010 & 2011 & 2012 & 2013 & $\begin{array}{c}\text { Average } \\
2009 \text { to } \\
2013\end{array}$ \\
\hline CPUT & 1 & 1 & 0.48 & 0.48 & 0.46 & 0.69 & 1 & 1 & 22 & 21 & 20 & 20 \\
\hline UCT & 1 & 1 & 1 & 1 & 1 & 1 & 1 & 1 & 1 & 1 & 1 & 1 \\
\hline CUT & 0.72 & 1 & 1 & 0.71 & 0.73 & 0.83 & 17 & 1 & 1 & 16 & 13 & 12 \\
\hline DUT & 0.48 & 0.53 & 0.71 & 0.58 & 0.59 & 0.58 & 21 & 20 & 15 & 19 & 17 & 21 \\
\hline UFH & 1 & 1 & 1 & 0.83 & 0.78 & 0.92 & 1 & 1 & 1 & 14 & 12 & 6 \\
\hline UFS & 1 & 1 & 1 & 1 & 1 & 1 & 1 & 1 & 1 & 1 & 1 & 1 \\
\hline UJ & 1 & 1 & 1 & 1 & 0.6 & 0.92 & 1 & 1 & 1 & 1 & 16 & 7 \\
\hline UKZN & 0.73 & 0.8 & 1 & 0.82 & 0.7 & 0.81 & 16 & 17 & 1 & 15 & 14 & 14 \\
\hline UL & 0.87 & 0.67 & 0.75 & 1 & 0.49 & 0.75 & 13 & 18 & 14 & 1 & 19 & 17 \\
\hline NMU & 0.5 & 0.45 & 0.62 & 1 & 1 & 0.71 & 20 & 21 & 16 & 1 & 1 & 19 \\
\hline NWU & 1 & 1 & 0.5 & 0.48 & 1 & 0.8 & 1 & 1 & 20 & 20 & 1 & 15 \\
\hline UP & 0.95 & 1 & 0.59 & 1 & 0.82 & 0.87 & 12 & 1 & 18 & 1 & 11 & 10 \\
\hline$R U$ & 1 & 1 & 1 & 1 & 1 & 1 & 1 & 1 & 1 & 1 & 1 & 1 \\
\hline UNISA & 1 & 1 & 0.61 & 1 & 0.45 & 0.81 & 1 & 1 & 17 & 1 & 21 & 13 \\
\hline SU & 1 & 1 & 1 & 1 & 1 & 1 & 1 & 1 & 1 & 1 & 1 & 1 \\
\hline TUT & 0.34 & 0.27 & 0.54 & 0.44 & 0.31 & 0.38 & 22 & 22 & 19 & 22 & 22 & 22 \\
\hline VUT & 1 & 1 & 1 & 0.64 & 0.69 & 0.87 & 1 & 1 & 1 & 17 & 15 & 11 \\
\hline UNIVEN & 0.73 & 0.84 & 1 & 1 & 1 & 0.92 & 15 & 16 & 1 & 1 & 1 & 8 \\
\hline WSU & 0.63 & 0.57 & 0.49 & 1 & 1 & 0.74 & 18 & 19 & 21 & 1 & 1 & 18 \\
\hline UWC & 0.53 & 1 & 1 & 1 & 1 & 0.91 & 19 & 1 & 1 & 1 & 1 & 9 \\
\hline WITS & 1 & 1 & 1 & 0.93 & 1 & 0.99 & 1 & 1 & 1 & 13 & 1 & 5 \\
\hline UZ & 0.86 & 0.91 & 1 & 0.63 & 0.52 & 0.78 & 14 & 15 & 1 & 18 & 18 & 16 \\
\hline
\end{tabular}

